\title{
Psychological characteristics and adjustment of College Students' Employment
}

\author{
Xin-Hua YAO and Yun-Heng ZHENG * \\ Beihua University ,Jilin, China \\ *Corresponding author: Yun-Heng ZHENG
}

Keywords: College students, Employment psychology, Debugging.

\begin{abstract}
With the rapid development of higher education, the development of China's higher education from "elite education" to "popular education" stage, the number of college graduates is increasing, this is not only on the professional quality of college students put forward higher requirements, but also for their psychological quality poses a challenge. The employment of college students is a systematic project, there are many factors affecting the employment psychology of college students, from the society, schools and families, as well as from the college students themselves. Starting from the psychological problems of college students, this paper summarizes the psychological characteristics of employment, and introduces how some college students adjust their employment psychology.

With the popularization of higher education in China, the number of college graduates has soared, and their employment has become an important issue in the current social development. Directional distribution of employment mode gradually eliminated, college graduates competitive employment, two-way choice has become an important way of employment. This provides more opportunities for the employment of college students, but also brings psychological pressure to the students, resulting in the employment psychological problems of the corresponding part of the students, it will not only affect college students during the professional learning, but also affect students' employment and occupation career and happiness of life, which affects the value orientation of contemporary college students then, affect the stability and development of society as a whole. The reason for this situation is that the school only pays attention to the imparting of knowledge in daily teaching, but neglects the cultivation of students' psychological quality.
\end{abstract}

\section{Psychological characteristics of College Students' Employment}

\section{A. Cognitive psychological problems}

The cognitive psychology of job hunting refers to the understanding and understanding of the students themselves, their occupation and their social environment in the process of choosing a job, and the reasoning and judgment of the thing in the process of choosing a job. There are some cognitive psychological problems in the process of employment of college students, including inaccurate self cognition and inaccurate external environment cognition. College students either have a certain inferiority complex, their quality and employment competitiveness evaluation is too low, dare not actively participate in employment competition, or very conceited, pretentious, think that their ability is very strong. Inferiority complex and conceited psychology are two representations of inaccurate self cognition in employment.

$\mathrm{B}$. The cognition of the peripheral environment is inaccurate

The inaccurate cognition of the peripheral environment mainly refers to the inaccurate understanding of the objective environment, such as the employment environment, the employment units, and so on. The main performance is that as the wave of high-tech development and economic globalization, many college students expect to high-tech companies, multinational companies or senior government departments work on what they think is hard work, some people would rather not work rather than settling. To learn and realize their ideal of life in the service of society, is the 
good wish of every students. However, there is a lack of in-depth understanding of some college students of high-tech companies, multinational companies or senior government departments, professional social demand analysis is not thorough, lack of the blind pursuit of these departments to estimate the employment environment. They either delay the choice of employment information, resulting in low utilization rate of information or changing careers, and default at will. In short, college students' inaccurate cognition of the external environment is one of the main reasons why many graduates can not find the desired career in the process of employment.

C. Emotional and psychological problems

Employment emotional psychology refers to some emotional problems before the employment of college students, or emotional fluctuations in the process of employment. Emotion is the barometer of College Students' mental health. When college students are employed, the mood appears impetuous and fluctuates, which is an inevitable phenomenon in the period of psychological growth. However, if the long-term emotional fluctuations, depression, anxiety and worry about personal gains and losses, will not only affect the college students' employment, but also affect the healthy development of College students.

\section{Self-adjustment of College Students' psychological problems in employment}

A. Strengthen the career planning education, establish the correct goal of life

The adjustment of College Students' employment psychological problems is a long-term and arduous work, which should be paid enough attention from the beginning of College Students' enrollment. At the beginning of the University, it is necessary to carry out career planning education for college students to help them establish a correct outlook on life. Career planning education is to let college students know themselves in a comprehensive way, according to their own professional conditions and conditions, to clear their own goals in life. Whatever you do, clear your goals is the first step. Only by making clear the goal, can we know the direction of our struggle. Everyone in the reality of ability, talent and wisdom are different, let the students to establish their own goals, although not necessarily can reach $100 \%$, but the objectives are of great significance to the success of college students occupation.

B. Strengthen career planning education, establish a correct view of career

Another effect of the occupation education planning is to make students know themselves, based on the understanding of the society, according to their own circumstances and conditions of employment ability, carry out and participate in the corresponding practice, practice of occupation, for their future job requirements and lay a solid foundation, the achievement of their occupation ideal. Occupation career planning education, not short-term, but should be long lasting, each year should at least once, to help students rational evaluation of self, self understanding, understanding of internal quality and their ability to have clear, its future development direction, and careful analysis of their advantages and disadvantages, test yourself the character and temperament, correctly treat the deficiencies and shortcomings of their own, in the face of setbacks and difficulties, play the role of incentives. At the same time, it objectively analyzes the employment environment, so that college students adjust their career expectations in a timely manner. The process of job search is essentially a two-way choice process, although graduates are selected by employers, but at the same time, employers are also selected by the job seekers, can not be preconceived positioning themselves in a vulnerable position. In the process of College Students' employment must be assertive, do not blindly cater to the employer, not others, for their ability to have self-confidence, accurate self positioning, to adjust the good mentality, condescend to face reality.

C. The employment guidance runs through the whole process of university education, and is carried out in stages and layers

Play an important role in the employment guidance to solve the employment psychological problems in college students, should not regard it as a temporary work, the formation of the correct concept of employment, not a few employment guidance course or lecture will be completed, it needs to gradually guide the days and months multiplying and subtle. Therefore, the day of 
employment guidance should start freshmen, according to the specific content of the employment guidance stage, multi form. In particular, we should seize the freshman year of college students, help them establish correct professional ideas, and guide students to change roles. On the issue of employment, the university is not a safe box, but the beginning of a new round of more intense competition, leading college students to conduct a preliminary career planning for their individual. By setting up the course of employment guidance, systematic guidance, guide them to lay a good foundation, improve self training ability, help them determine the occupation development direction according to their own characteristics, and to provide employment information for students to actively participate in various forms of "double" activities, happily go to work.

D. Strengthen the ability of psychological adjustment training, improve the psychological quality of College Students

Employment psychological health education is to provide psychological help for psychological problems in the process of employment of the graduates from the outlook on life, world outlook, values and other aspects to guide the graduates out of the false self, starting with the analysis of the employment psychological analysis of the adverse consequences of the current employment situation, and help students to establish a correct concept of employment. College students in the employment process encountered various difficulties and psychological pressure is inevitable, the key is how to effectively face the pressure and ease the psychological pressure, which requires the graduates to master some skills and methods of psychological adjustment, help yourself to respond in a timely manner and resolve psychological problems. Therefore, to strengthen the employment psychological counseling education and employment psychological counseling in college students, as far as possible to understand more widespread psychological problems, targeted to spread knowledge of mental health education of college students, strengthen college students' psychological adjustment ability training, guide students to learn to use positive self suggestion, catharsis, empathy, self consolation, outdoor activities, relaxation training method of psychological adjustment, adjust the positive attitude, calm in the face of difficulties and setbacks, always maintain optimism and positive attitude.

E. Comprehensively improve their quality and ability to achieve a successful career choice

First of all, to consolidate their professional knowledge, expand the breadth and depth of professional knowledge, pay attention to the use of basic theory. In this way, we can give full play to our ability in practice, at the same time, we should pay attention to the improvement of our own quality and the cultivation of comprehensive ability. A college student comprehensive level of quality, ability decides directly the result of employment, college students should be oriented to the needs of society, to broaden their knowledge, strengthen the training of scientific research ability and practice ability, strengthen innovation consciousness, market consciousness and competition consciousness, improve their competitiveness in the job market, to enhance the employment confidence. College students should fully believe in their own ability in the process of job hunting, take the initiative to attack, confidently sell themselves, show themselves, and achieve a successful career choice.

\section{Acknowledgements}

The Department of education of Jilin province " 13th Five-Year " ordinary program: analysis of College Students' employment psychology and negative peer support "education mode" (GH170074) is one of the results.

\section{References}

[1] Wang Benxian. Analysis of the political situation and reasons of College Students' ideological education employment [J]. Journal of Xuzhou Normal University (SOCIAL SCIENCE EDITION), 2010, (3).

[2] Zhang Lei topology. Construction of [J/OL]. modern communication, college students' 
employment psychological problems intervention mechanism: (2017-05-18).

[3] Wang Xiuyu. Analysis of the ways to cultivate college students' good employment psychology [J]. Journal of Liaoning University of Technology (SOCIAL SCIENCES EDITION), 2016,18 (05): 97-99.

[4] Li Jing. Current situation of College Students' employment psychology and ways to explore [J]. Journal of Shanxi Datong University (NATURAL SCIENCE EDITION), 2016,32 (04): 85-87.

[5] Dong Jingjing, Yao Benxian. Post-90s college students' Employment Psychological Problems Investigation [J]. social psychology science, 2015,30 (10): 84-89. 